\title{
ResearchArticle
}

\section{Anti-microbial activity of spices black cardamom, mustard seed and liquorice against $V$. cholera, $V$. parahaemolyticus and V.vulnificus}

NAVEEN KUMAR SHUKLA AND UMA SHANKAR

\begin{abstract}
SUMMARY
There are several water-borne diseases which are highly pathogenic for humans. Among all, Vibrio genus plays a major role. Vibrio cholerae, a gram negative anaerobe, is one of the most ancient and major water borne pathogen which causes fatal disease, cholera. This study chiefly focuses on the natural or plant derived products which could be used against Vibrio. In this work, 10 pond water samples were collected and investigated for presence or absence of pathogenic Vibrio species. A rapid method, multiplex PCR, of identification has been applied for determining the species. Out of 10, 8 samples showed presence of Vibrio species in them when cultured on selective media. The identified isolates of $V$. cholera, V. parahaemolyticus and V. vulnificus were then tested against three common spices, black cardamom (Amomum subulatum), mustard seed (Brassica nigra) and liquorice (Glycyrrhiza glabra), extracts for their antibacterial property using agar well diffusion method. The antimicrobial assay result of spices showed a maximum activity by aqueous extract liquorice (Glycyrrhiza glabra) of $23 \pm 0.52(\mathrm{~mm}$ ) against V.vulnificus followed by mustard seed (Brassica nigra) of 22.1 $\pm 0.60(\mathrm{~mm})$ against V.vulnificus.
\end{abstract}

Key Words : Black cardamom, Mustard seed, Liquorice, mPCR, TOX gene, Vibrio species, Antibacterial activity

How to cite this article : Shukla, Naveen Kumar and Shankar, Uma (2016). Anti-microbial activity of spices black cardamom, mustard seed and liquorice against V. cholera, V. parahaemolyticus and V. vulnificus. Internat. J. Plant Sci., 11 (2): 218-223, DOI: 10.15740/HAS/ IJPS/11.2/218-223.

Article chronicle : Received : 25.01.2016; Revised : 13.04.2016; Accepted : 27.05.2016

\section{MEMBERS OF THE RESEARCH FORUM}

Author to be contacted :

UMA SHANKAR, Division of Biotechnology, Cyto Gene Research and

Development, LUCKNOW (U.P.) INDIA

Email: publication.cytogene@gmail.com 